\title{
POLA PENYEBARAN CAPUNG (ODONATA) DI KAWASAN TAMAN WISATA ALAM SURANADI LOMBOK BARAT
}

\author{
M. Liwa Ilhamdi ${ }^{1}$ \\ ${ }^{1}$ Dosen Pendidikan Biologi FKIP Universitas Mataram \\ liwa_ilhamdi@unram.ac.id
}

\begin{abstract}
ABSTRAK
Tujuan penelitian ini adalah untuk menganalisis pola distribusi capung (Odonata) di Kawasan Taman Wisata Alam Suranadi. Jenis penelitian ini deskriptif eksploratif yang dilakukan pada bulan Mei 2017. Metode yang digunakan dalam pengambilan data ialah metode penangkapan capung dengan jaring serangga mengikuti empat jalur transek yaitu jalur pinggir kiri hutan, jalur pinggir kanan hutan, jalur tengah dan jalur air. Pengambilan data dilakukan sebanyak 2 kali pengulangan dalam waktu 1 bulan pada pagi hari pukul $08.00-11.00$ wita dan sore hari pukul 15.00-17.00 wita Perhitungan indeks pola penyebaran capung menggunakan rumus dari Southwood. Hasil penelitian menunjukkan bahwa (1) Jumlah spesies capung yang ditemukan di Kawasan Taman Wisata Alam Suranadi terdiri dari 19 spesies yang termasuk kedalam 5 famili (2) Pola penyebaran capung berkategori mengelompok (15 spesies) dan pola penyebaran merata (4 spesies).
\end{abstract}

Kata-kata Kunci: Capung, Pola Penyebaran, Suranadi.

\begin{abstract}
The aim of this research is to analyze the distribution pattern of the dragonflies (Odonata) in the Area of Nature Park Suranadi. This is an explorative descriptive study conducted in May 2017. The method used in data collection is survey method with sweeping net technique following observation path (Left Edge, Right Edge, Central Line and Water Line). Data retrieval is done 2 times repetition within 1 month in the morning at $08.00-11.00 \mathrm{pm}$ and afternoon at 15.00-17.00 pm. The pattern analysis of the distribution of dragonflies using the formula variance value of Southwood. The results showed that (1) the number of species of dragonflies found in Suranadi Nature Park Area consists of 19 species belonging to 5 families (2) distribution pattern of dragonflies are distributed in groups (15 species) and uniform distribution pattern (4 species).
\end{abstract}

Key Words: Dragonflies, distribution Patterns, Suranadi. 


\section{PENDAHULUAN}

Keberadaan serangga dalam suatu ekosistem mempunyai peranan yang sangat penting (Ilhamdi, 2012). Capung merupakan salah satu serangga yang memiliki peranan penting bagi keberlangsungan ekosistem yakni berperan sebagai indikator pencemaran lingkungan. Keberadaan capung di dalam suatu lingkungan dapat dijadikan sebagai indikasi untuk melihat kondisi lingkungan (Koneri, 2014). Capung dapat dijadikan sebagai indikator air bersih yang bermanfaat untuk memonitor kualitas air di sekitar lingkungan. Capung melakukan proses perkembangbiakan pada lingkungan perairan yang sehat. Kondisi perairan yang tercemar, dapat menyebabkan terganggunya siklus hidup capung sehingga mengakibatkan jumlah populasi capung jarum menurun. Oleh karena itu, perubahan dalam populasi capung dapat dijadikan sebagai langkah awal untuk menandai adanya polusi (lingkungan yang tercemar) (Susanti, 1998).

Pada ekosistem yang ditempatinya capung dan capung jarum berperan menjaga keseimbangan rantai makanan dimana capung jarum berperan sebagai serangga predator yang bertindak sebagai musuh alami yang dapat mengurangi populasi hama tanaman pangan sehingga mampu menekan dinamika populasi serangga yang berpotensi sebagai hama pertanian (Rizal, 2014). Hal ini menunjukkan posisi penting keberadaan capung dalam keseimbangan ekologi. Lebih lanjut Hidayah (2008) menyatakan tanpa kehadiran capung, maka kehidupan suatu ekosistem akan terganggu dan tidak akan mencapai suatu keseimbangan.
Sejalan dengan pemikiran tersebut, menurut Drozd (2011) kehadiran capung sangat dipengaruhi oleh kondisi lingkungan yang meliputi lingkungan air dan struktur hutan karena air yang tercemar akan mengganggu kehidupan nimfa capung, begitu juga dengan hutan, hutan yang heterogen memiliki kemelimpahan populasi capung yang lebih tinggi. Keanekaragaman capung yang tinggi pada suatu kawasan mengindikasikan kawasan tersebut belum tercemar karena lingkungan tersebut mendukung kehidupan nimfa capung (Ansori, 2009).

Salah satu kawasan hutan yang berperan penting dalam mendukung kehidupan capung ialah Kawasan Taman Wisata Alam (TWA) Suranadi. Kawasan TWA Suranadi sebagai suatu kawasan hutan konservasi sangat berperan penting dalam mendukung kehidupan berbagai fauna yang saling berinteraksi untuk mewujudkan keseimbangan ekosistem. Mengingat pentingnya fungsi dari capung terhadap kesehatan ekosistem perairan hutan, baik dari fungsi sebagai bioindikator maupun sebagai agen pengendalian hayati (biokontrol) maka penelitian tentang capung ini penting dilakukan.

\section{METODE PENELITIAN}

Penelitian ini dilaksanakan pada bulan Mei 2017 di Kawasan Taman Wisata Alam (TWA) Desa Suranadi, Kecamatan Narmada, Kabupaten Lombok Barat, Provinsi Nusa Tenggara Barat. Alat dan bahan yang digunakan dalam penelitian adalah jaring serangga, teropong binokuler, buku identifikasi capung, alat tulis, kamera dan jarum suntik sedangkan bahan terdiri dari kertas papilot, formalin 4\% dan kertas label. 
Proses pengambilan data dalam penelitian ini menggunakan metode penangkapan capung mengikuti jalur transek yang telah ditentukan berdasarkan hasil observasi. Jalur transek yang digunakan terdiri dari empat jalur yaitu jalur kiri, jalur kanan, jalur tengah dan jalur air. Sampel capung yang diambil dalam penelitian ini adalah capung dewasa. Pengambilan sampel dilakukan pada sepanjang garis transek dengan menggunakan jaring serangga. Pengambilan data dilakukan sebanyak 2 kali pengulangan dalam waktu 1 bulan. Penangkapan capung dilakukan pada pagi hari mulai pukul $08.00-11$. 00 wita dan sore hari mulai pukul $15.00-17.00$ wita. Hal ini dilakukan karena capung termasuk kelompok serangga yang aktif pada siang hari. Pengambilan gambar menggunakan kamera DSLR dilakukan pada semua capung yang dijumpai di lokasi penelitian agar lebih mudah dalam mengidentifikasi apabila terdapat capung yang belum diketahui spesiesnya. Selain itu, dilakukan pengamatan menggunakan teropong binokuler untuk mengamati spesies capung yang sulit ditangkap.

Capung yang tertangkap disuntik menggunakan jarum suntik kemudian dikeringkan dibawah sinar matahari. Hal ini dilakukan agar warna cemerlang capung tidak memudar, setelah itu disimpan kedalam kertas-kertas papilot dengan posisi sayap terlentang diatas tubuh. Sampel kemudian diidentifikasi dan dihitung jumlah individunya. Proses identifikasi dilakukan berdasarkan karakteristik dari morfologi eksternal seperti warna venasi sayap, ukuran sayap, bentuk dan posisi sayap, warna dan bentuk tubuh dan perilaku terbang dengan menggunakan buku identifikasi Bun et al., 2010; Samways., 2008 dan Sigit et al., 2013. Analisis data yang digunakan untuk menghitung pola penyebaran capung adalah menggunakan rumus-rumus sebagai berikut:

$\mathbf{S}^{2}=\frac{\sum(x-\bar{x}) 2}{n-1}$ dimana, $\overline{\mathbf{x}}=\frac{\sum x}{n}$

Keterangan:

$\mathrm{x} \quad$ : Jumlah individu tiap jenis

$\mathrm{n} \quad$ : Jumlah jalur pengamatan

$\overline{\mathrm{x}} \quad$ : Jumlah total individu

Jika

$S^{2}=1$ pola penyebaran acak

$S^{2}>1$ pola penyebaran mengelompok

$S^{2}<1$ pola penyebaran teratur

(Ludwig, 1988)

\section{HASIL DAN PEMBAHASAN}

Hasil penelitian yang dilakukan di Kawasan Taman Wisata Alam Suranadi pada bulan Mei 2017 diperoleh spesies capung dari subordo Anisoptera dan Zygoptera sebanyak 19 spesies yang termasuk dalam 5 famili. Nama famili dan spesies capung dapat dilihat pada Tabel 1 . 
Tabel 1 Jenis Capung (odonata) di Kawasan Taman Wisata Alam Suranadi

\begin{tabular}{|c|c|c|c|c|}
\hline No & Subordo & Famili & No & Nama Latin \\
\hline \multirow{12}{*}{1} & \multirow{12}{*}{ Anisoptera } & \multirow{12}{*}{ Libellulidae } & 1 & Orthetrum sabina \\
\hline & & & 2 & Orthetrum chrysis \\
\hline & & & 3 & Diplacodes trivialis \\
\hline & & & 4 & Neurothemis ramburii \\
\hline & & & 5 & Neurothemis terminata \\
\hline & & & 6 & Aethriamanta brevipennis \\
\hline & & & 7 & Pantala flavescens \\
\hline & & & 8 & Onycothemis culminicola \\
\hline & & & 9 & Trithemis furva \\
\hline & & & 10 & Tholymis tilliagra \\
\hline & & & 11 & Potamarcha congener \\
\hline & & & 12 & Lathrecista asiatica \\
\hline \multirow{7}{*}{2} & \multirow{7}{*}{ Zygoptera } & \multirow{3}{*}{ Coenagrionidae } & 13 & Pseudagrion pilidorsum \\
\hline & & & 14 & Pseudagrion pruinosum \\
\hline & & & 15 & Agriocnemis femina \\
\hline & & \multirow{2}{*}{ Chlorocyphidae } & 16 & Libellago rufescens \\
\hline & & & 17 & Libellago lineate \\
\hline & & Euphaeidae & 18 & Euphaea ochracea \\
\hline & & Platycnemididae & 19 & Copera marginipes \\
\hline
\end{tabular}

Berdasarkan Tabel 1, spesies capung (odonata) yang ditemukan terdiri dari 19 spesies, 12 spesies termasuk dalam subordo Anisoptera dan 7 spesies termasuk dalam subordo Zygoptera. Subordo Anisoptera yang terdiri dari satu famili, yaitu famili Libellulidae (Orthetrum Sabina, Orthetrum chrysis, Diplacodes trivialis Neurothemis ramburii, Neurothemis terminata, Aethriamanta brevipennis, Pantala flavescens, Onycothemis culminicola Trithemis furva, Tholymis tilliagra, Potamarcha congener, Lathrecista asiatica). Subordo Zygoptera yang terdiri dari empat famili, yaitu famili Coenagrionidae
(Pseudagrion pilidorsum, Pseudagrion pruinosum dan Agriocnemis femina), famili Chlorocyphidae (Libellago rufescens dan Libellago lineata), serta famili Euphaeidae (Euphaea ochracea) dan famili Platycnemididae (Copera marginipes).

Jumlah capung yang diperoleh dalam penelitian ini banyak ditemukan dari famili Libellulidae terutama Orthetrum sabina dan Diplacodes trivialis. Jumlah capung yang paling sedikit ditemukan adalah Onycothemis culminicola, Trithemis furva, Potamarcha congener, dan Libellago lineate. 
Kebanyakan jenis capung yang ditemukan di lokasi jalur 4 yaitu jalur air. Hal ini terjadi karena jalur air ini ada aliran sungai yang mengalirkan air dari mata air sehingga capung berkumpul dan hidup di tempat tersebut.

Patty (2006) dan Safitri (2014) menyatakan bahwa Orthetrum sabina dan Diplacodes trivialis merupakan spesies capung yang mudah ditemukan pada setiap lokasi penelitian. Hal ini erat kaitannya dengan kemampuannya beradaptasi pada musim kemarau dan musim hujan serta kemampuannya yang dapat hidup di semua habitat.

Berdasarkan hasil analisis pola penyebaran capung di Hutan Wisata Alam Suranadi dapat dilihat pada Tabel 2.

Tabel 2. Pola penyebaran Capung (odonata) di Kawasan Taman Wisata Alam Suranadi

\begin{tabular}{|c|c|c|c|c|c|c|c|c|c|}
\hline \multirow{2}{*}{ No } & \multirow{2}{*}{ Spesies } & Kanan & Tengah & Kiri & Air & \multirow{2}{*}{$\mathrm{x}$ total } & \multirow{2}{*}{$\overline{\mathbf{X}}$} & \multirow{2}{*}{$\mathbf{S}^{2}$} & \multirow{2}{*}{$\begin{array}{c}\text { Pola } \\
\text { penyebaran }\end{array}$} \\
\hline & & $\mathbf{X}_{1}$ & $\mathbf{X}_{2}$ & $\mathbf{X}_{3}$ & $\mathbf{X}_{4}$ & & & & \\
\hline 1 & Orthetrum Sabina & 25 & 2 & 110 & 24 & 161 & 40.25 & 4860.19 & Berkelompok \\
\hline 2 & Orthetrum chrysis & 8 & 0 & 11 & 34 & 53 & 13.25 & 526.69 & Berkelompok \\
\hline 3 & Diplacodes trivialis & 1 & 0 & 58 & 12 & 71 & 17.75 & 945.19 & Berkelompok \\
\hline 4 & $\begin{array}{l}\text { Neurothemis } \\
\text { ramburii }\end{array}$ & 5 & 3 & 6 & 13 & 27 & 6.75 & 136.69 & Berkelompok \\
\hline 5 & $\begin{array}{l}\text { Neurothemis } \\
\text { terminata }\end{array}$ & 2 & 1 & 1 & 0 & 4 & 1.00 & 3.00 & Berkelompok \\
\hline 6 & $\begin{array}{l}\text { Aethriamanta } \\
\text { brevipennis }\end{array}$ & 2 & 0 & 7 & 5 & 14 & 3.50 & 36.75 & Berkelompok \\
\hline 7 & Pantala flavescens & 3 & 0 & 8 & 6 & 17 & 4.25 & 54.19 & Berkelompok \\
\hline 8 & $\begin{array}{l}\text { Onycothemis } \\
\text { culminicola }\end{array}$ & 0 & 0 & 0 & 1 & 1 & 0.25 & 0.19 & Teratur \\
\hline 9 & Trithemis furva & 0 & 0 & 0 & 2 & 2 & 0.50 & 0.75 & Teratur \\
\hline 10 & Tholymis tilliagra & 0 & 1 & 3 & 0 & 4 & 1.00 & 3.00 & Berkelompok \\
\hline 11 & $\begin{array}{l}\text { Potamarcha } \\
\text { congener }\end{array}$ & 0 & 0 & 1 & 1 & 2 & 0.50 & 0.75 & Teratur \\
\hline 12 & $\begin{array}{l}\text { Lathrecista } \\
\text { asiatica }\end{array}$ & 0 & 3 & 1 & 1 & 5 & 1.25 & 4.69 & Berkelompok \\
\hline 13 & $\begin{array}{l}\text { Pseudagrion } \\
\text { pilidorsum }\end{array}$ & 0 & 23 & 3 & 68 & 94 & 23.50 & 1656.75 & Berkelompok \\
\hline 14 & $\begin{array}{l}\text { Pseudagrion } \\
\text { pruinosum }\end{array}$ & 0 & 1 & 0 & 34 & 35 & 8.75 & 229.69 & Berkelompok \\
\hline 15 & $\begin{array}{l}\text { Agriocnemis } \\
\text { femina }\end{array}$ & 0 & 3 & 0 & 29 & 32 & 8.00 & 192.0 & Berkelompok \\
\hline 16 & Libellago rufescens & 0 & 5 & 0 & 0 & 5 & 1.25 & 4.69 & Berkelompok \\
\hline 17 & Libellago lineate & 0 & 0 & 0 & 2 & 2 & 0.50 & 0.75 & Teratur \\
\hline 18 & Euphaea ochracea & 0 & 1 & 0 & 5 & 6 & 1.50 & 675 & Berkelompok \\
\hline 19 & Copera marginipes & 1 & 3 & 0 & 5 & 9 & 2.25 & 15.19 & Berkelompok \\
\hline & Total $(N)$ & 47 & 46 & 209 & 242 & 544 & 136 & 8677.88 & Berkelompok \\
\hline
\end{tabular}


Berdasarkan hasil perhitungan pola penyebaran capung pada Tabel 2 diperoleh pola penyebaran capung secara keseluruhan adalah berkelompok, kecuali spesies Onycothemis culminicola, Trithemis furva dan Libellago lineata yang memiliki pola disribusi teratur. Berbedanya pola pola penyebaran capung dalam penelitian ini berkaitan dengan kemampuan capung untuk beradaptasi terhadap habitat yang ditempati. Umumnya spesies yang memiliki pola penyebaran secara mengelompok disebabkan karena adanya faktor pembatas terhadap keberadaan populasi tersebut, seperti kecepatan arus perairan karena ada beberapa spesies yang hanya dapat hidup pada arus yang lambat dan tenang serta adapula yang hidup di perairan yang memiliki arus cepat (Aswari, 2011). Pola penyebaran mengelompok berarti bahwa populasi sebaran individu capung dalam populasi itu mengelompok (Pamungkas, 2015). Menurut Odum (1993) Sifat penyebaran mengelompok umumnya dimiliki oleh serangga karena kecenderungan untuk mengelompok, berkumpul dari berbagai derajat mewakili sifat yang paling umum. Berbeda halnya dengan spesies yang memiliki pola penyebaran teratur. Spesies yang memiliki pola penyebaran teratur disebabkan karena sumber daya yang dibutuhkan untuk keberlangsungan hidup capung tersedia di seluruh Kawasan Taman Wisata Alam suranadi.

\section{KESIMPULAN}

Berdasarkan hasil penelitian dapat disimpulkan bahwa (1) spesies capung (Odonata) yang ditemukan di Kawasan Taman Wisata Alam Suranadi terdiri dari 19 spesies yang termasuk kedalam 5 famili. (2) Pola penyebaran capung di kawasan Taman Wisata Alam Suranadi termasuk kategori mengelompok (15 spesies) dan pola penyebaran teratur (4 spesies).

\section{DAFTAR PUSTAKA}

Ansori, I. 2009. Kelimpahan dan Dinamika Populasi Odonata Berdasarkan Hubungannya dengan Fenologi Padi di Beberapa Persawahan sekitar Bandung Jawa Barat. Jurnal exacta, 7(2): 67-75.

Aswari, P. 2011. Keanekaragaman Seranggga Gunung Ciremai. Bogor: Puslit-LIPI

Bun, T.H., Keng, W.L and Hamalainen, M. 2010. A photographic guide to the Dragonflies of Singapore. Singapore: Kepmedia International.

Dolny, A., Harabis, F., Bárta, D., Lhota, S and Drozd, P. 2012. Aquatic Insects Indicate Terrestrial Habitat Degradation: Changes in Taxonomical Structure and Functional Diversity of Dragonflies in Tropical Rainforest of East Kalimantan. Tropical Zoology, 25(3): 141-157.

Drozd, P. 2011. Dragonflies (Odonata) In The Borneo Rain Forest as Indicators of Change in Biodiversity Resulting From Forest Modofication and Destruction. Tropical Zoology, 24(1): 63-86. 
Hidayah, S.N. 2008. Keanekaragaman dan aktivitas Capung (ordo: odonata) di kebun raya bogor. Skripsi. Bogor: Institut Pertanian Bogor.

Ilhamdi ML, 2012, Keanekaragaman Serangga dalam Tanah di Pantai Endok Lombok Barat, Jurnal Pijar MIPA,7(2): 55-59.

Koneri, R dan Tallei, T. 2014. Kelimpahan Populasi Capung jamur (Zygoptera) di Kawasan Taman Nasional Bogani Nani Wartabone. Jurnal Bioslogos, 4(2): 42-47.

Kramadibrata, I. 1995. Ekologi Hewan. Bandung: ITB

Ludwig, JA, 1988, Statistical Ecology, John Wiley, Singapore

Odum, E.P. 1993. Dasar-dasar Ekologi. Yogyakarta: Gadjah Mada University Press.

Orr, A.G. 2001. An Annotated Checklist of the Odonata of Brunei with Ecologicalnotes and Descriptions of Hitherto Unknown Males and Larvae. International Journal of Odonatology, 4(2): 167-220.

Pamungkas, D.W. 2015. Keragaman Jenis Capung dan Capung Jarum
(Odonata) di Beberapa Sumber Air di Magetan, Jawa Timur. Proseding Seminar Nasional Masy Biodiversitas Indonesia, 1(6): 12951301.

Patty, N. 2006. Keanekaragaman Jenis Capung (Odonata) di Situ Gintung Ciputat, Tanggerang. Skripsi. Jakarta: Universitas Islam Negeri Syarif Hidayatullah Jakarta.

Rizal, S dan Hadi, M. 2014. Inventarisasi Jenis Capung (Odonata) Pada Areal Persawahan di Desa Pundenarum Kecamatan Karangawen Kabupaten Demak. Jurnal Bioma, 17(1): 16-20.

Safitri, A.D. 2014. Kajian Komunitas Capung (Odonata) pada Kondisi Rona Lingkungan yang Berbeda di Ekosistem Sawah Kelurahan Pandanwangi Malang. Skripsi. Malang: Universitas Negeri Malang.

Samways, M.J. 2008. Dragonflies and Damselfies of South Africa. Bulgaria: Pensoft Publishers.

Sigit, W., Feriwibisono, B., Nugrahani, M.P., Putri, B dan Makitan, T. 2013. Naga Terbang Wendit. Malang: Indonesia Dragonfly Society.

Susanti, S. 1998. Mengenal Capung. Bogor: Puslitbang LIPI. 